\title{
Tracing an Ethic of Care in the Policy and Practice of the Troubled Families Programme
}

\author{
Sue Bond-Taylor \\ School of Social and Political Sciences, University of Lincoln \\ E-mail: sbtaylor@lincoln.ac.uk
}

\begin{abstract}
Drawing upon the Trace method developed by Selma Sevenhuijsen (2004), this paper has traced the discourse constructed in two key Troubled Families Programme (TFP) policy documents through the lens of care ethics, highlighting tensions between 'care' and 'justice' orientations in the neoliberal family intervention model. It is argued that whilst the family intervention model advocated has the potential to provide families with support underpinned by an ethic of care, the TFP's managerialist tendencies also create challenges to the integration of care ethics within such services. Given that the programme's financial framework generates considerable opportunity for local variation in policy implementation, the ethics of care offer a valuable moral framework by which to evaluate local practice. Moreover, engaging with a distinctly feminist ethic of care renders visible to family support services the inequalities produced through the gendered distribution of 'caring' responsibilities, and highlights the need for interventions to address rather than reinforce these inequalities.
\end{abstract}

Keywords: Troubled families, family interventions, neoliberalism, care ethics, feminism.

At the 2013 annual conference of the Association of Directors of Children's Services, Louise Casey gave a speech about the Troubled Families Programme (TFP), focusing upon the importance of the relationship between family and support worker:

In many ways we give messages not to create 'dependency', not to be soft or kind. I do not believe in this, as we all need to rely on others and we all need kindness. This approach is grounded in the reality of a family's situation. We can care and we demonstrate this through respect, trust and reliability, challenge, authenticity and persistence. (Casey, 2013)

Casey refers to a number of key values - trust, respect, reliability - and emphasises dependency as a common feature of human experience. In doing so, she advocates an approach to working with families informed by what Carol Gilligan (1982) described as the ethics of care. Yet, this depiction of family interventions sits uneasily alongside critical academic concerns about the potentially invasive and oppressive neoliberal regime constructed in the name of the TFP (Crossley, 2016).

This paper considers the extent to which care ethics might underpin TFP policy and the key worker model of family intervention advocated. I draw upon the body of work which has developed from Gilligan's (1982) thesis, in particular using Sevenhuijsen's (2004) Trace method of policy analysis, in order to explore the construction of care 
ethics discourses within two documents which were instrumental in the development of the TFP. Listening to Troubled Families (Casey, 2012) claimed to highlight the problems experienced by 'troubled' families, and therefore to present an urgent case for the programme. Working with Troubled Families: A Guide to the Evidence and Good Practice (DCLG, 2012) built upon this by proposing a model for working with families to address these problems. Together they represent the central discursive framework on 'troubled families' which emerged from DCLG and which underpins the programme. Whilst there is not the scope here to draw comparisons with empirical findings about local practice, some of the implications of adopting (or ignoring) care ethics within the delivery of services to support families with multiple disadvantages will be considered.

\section{Ethics of care}

Gilligan (1982) identified the ethics of care as an alternative to dominant notions of 'universalistic morality' (Tronto, 1993: 27) pervading psychology and moral philosophy, in particular the work of her Ph.D. supervisor Lawrence Kohlberg. His theory of moral development emphasised the superiority of Kantian principles of 'justice', based on a universal viewpoint characterised by impartiality, detachment and rationality (Squires, 1999: 142). By contrast, Gilligan's research with female participants identified a different moral voice which emphasised symbolically 'feminine' principles of 'care' rather than 'masculine' principles of 'justice'. This morality of care focused upon the importance of interconnectedness, maintaining relationships and harm avoidance, rather than impartiality and detachment, and emphasised situated and contextual decision making, rather than the universal application of rules. The binary divisions between 'care' and 'justice' emerging from this debate are summarised in Table 1, although they have since been subject to considerable contestation.

Tronto $(1993,2013)$ has pointed out that emphasising an essential feminine caring morality reinforces women's disproportionate responsibility for care. She therefore argues that care theory must establish a feminist ethic of care premised upon the democratic distribution of responsibilities for care, the promotion of equality and addressing privileged irresponsibility amongst powerful groups. Within this context, care emerges not as an alternative model to justice but as an alternative model of justice (Sevenhuijsen, 1998). More recent care perspectives have also developed to offer a critique of neoliberalism rather than (as in earlier perspectives) liberalism or liberal justice (Robinson, 2010; Tronto, 2013; Ward, 2015). These criticisms have included: neoliberalism's preference for market principles to govern the allocation of resources and the commodification of every aspect of human life (Held, 2002); the application of contractual models to the provision of care and responsibilisation for self-care (Ward, 2015); and the ways in which the emphasis on formal legal equality masks the positions of substantive inequality from which people start - what Tronto (2013) refers to as the 'myth of the clean slate'.

Sevenhuijsen (2004) advocates feminist care ethics as a political strategy for analysing the discourses constructed within policy documents, generating the Trace methodology for this purpose. According to Sevenhuijsen, the ethics of care adds two dimensions to analyses of policy. Firstly, it acts as a lens through which the normative frameworks can be rendered visible, providing the analyst with 'a set of sensitizing questions and concepts that should assist in digging out the relevant elements in policy documents' (2004: 16). 
Table 1. Comparison of Gilligan's morality of care with Kohlberg's morality of justice (Hughes, 2002: 127)

\begin{tabular}{|c|c|c|}
\hline & $\begin{array}{l}\text { Morality of care and } \\
\text { responsibility (Gilligan) }\end{array}$ & $\begin{array}{l}\text { Morality of justice } \\
\text { (Kohlberg) }\end{array}$ \\
\hline Primary moral imperative & Non-violence/care & Justice \\
\hline \multirow[t]{7}{*}{ Components of morality } & Relationships & Sanctity of the individual \\
\hline & Responsibility for self and & Rights of self and others \\
\hline & others & Reciprocity \\
\hline & Care & Respect \\
\hline & Harmony & Rules/legalities \\
\hline & Compassion & \\
\hline & Selflessness/self-sacrifice & \\
\hline Nature of moral dilemma & $\begin{array}{l}\text { Threats to harmony and } \\
\text { relationships }\end{array}$ & Conflicting rights \\
\hline $\begin{array}{l}\text { Determination of moral } \\
\text { obligation }\end{array}$ & Relationships & Principles \\
\hline $\begin{array}{l}\text { Cognitive processes for } \\
\text { resolving dilemmas }\end{array}$ & Inductive thinking & $\begin{array}{l}\text { Logical-deductive } \\
\text { thinking }\end{array}$ \\
\hline View of self as moral agent & Connected, attached & Separate, individual \\
\hline Philosophical orientation & $\begin{array}{l}\text { Phenomenological } \\
\text { (contextual relativism) }\end{array}$ & $\begin{array}{l}\text { Rational (universal } \\
\text { principle of justice) }\end{array}$ \\
\hline
\end{tabular}

Policy documents act as 'vehicles of normative paradigms' (Sevenhuijsen, 2004: 14-15), configuring 'knowledge' in ways which construct social problems and privileging certain speaking positions. In reflecting upon the TFP in this way, we can draw upon critiques of the programme as 'policy-based evidence' rather than evidence-based policy making (Gregg, 2010; Hayden and Jenkins, 2014), founded upon unreliable and unethical social research (Bailey, 2012; Levitas, 2012). In that sense, the policy documents have been described as constructing the 'problem' of 'troubled families' as a 'factoid' (Levitas, 2012) or 'doxa - a situation where the arbitrary appears natural and where important issues remain unspoken or taken for granted' (Crossley, 2016: 1).

Secondly, care ethics provide a framework of moral values, a standard by which policy and practice can be assessed. A Trace analysis requires the researcher to draw upon the care ethics literature that has identified the qualities of 'care-full' policy and practice. Consequently, I distil from the literature a number of principles of care. Tronto (1993) provides four principles necessary for the integrity of care: attentiveness, responsibility, competence and responsiveness. Barnes (2012) has noted two further principles, including Sevenhuijsen's (2003) principle of trust and Engster's (2007) principle of respect. Tronto has argued that these combine to create a form of solidarity or 'caring with' (Tronto, 2013). To these six principles of care, I add three further principles described by Smart and Neale (1999) as necessary in work with children and families: actuality, recognition of selfhood, and recognition of loss. I contend that together these provide a set of moral values and practices underpinned by a broader theme of relationality, which can be used to facilitate a Trace analysis of 'care' practices in TFP policy. 


\section{Tracing the ethics of care in the TFP}

It is impossible here to analyse the two TFP reports in detail, so they are used for the following purposes. Firstly, the Working with Troubled Families report is visited to explore the TFP family intervention model from a care ethics perspective, identifying both aspects of care ethics within the model, and challenges to care ethics also evident within the report. Secondly, in highlighting the centrality of gender equality to a feminist ethic of care, I use the Listening to Troubled Families report to illustrate the highly gendered constructions evident in both the identification of the 'problem' and the model proposed as the solution.

\section{Identifying care ethics in the Working with Troubled Families model}

This work requires a single dedicated worker to walk in the shoes of these families every day. To look at the family from the inside out, to understand its dynamics as a whole, and to offer practical help and support. (DCLG, 2012: 4)

Whilst the TFP policy documents never claim to pursue an ethic of care within the programme, this depiction of family focused interventions in the TFP appears to reflect key care ethics principles. The shift in perspective to assess families 'from the inside out rather than the outside in' (DCLG, 2012: 26) demonstrates attentiveness to the unique contexts of family life and the interconnectedness between individuals identifying as 'family'. The report argues that 'families with the most complex and entrenched problems often do not benefit from services they receive because [the services] do not take the full family situation and context into account' (DCLG, 2012: 10). Services have tended to provide numerous individualised responses to specific problems (e.g. child protection or anti-social behaviour) as if they are isolated from one another. They reflect a 'justice' orientation which emphasises rationality, and fail to consider the constraints on 'choice' which accompany caring and interpersonal obligations. The introduction of a 'holistic' whole family perspective, by contrast, responds to family dynamics in a contextualised and situated way. The shift in focus to supporting each specific family rather than 'troubled families' as a whole generates 'bespoke' responses which draw upon family strengths, echoing the care ethics principle of actuality.

In addition, the key worker does not merely provide the message about what needs to change, but also supports families to make these changes and understand how to do so. Much of their time is spent providing hands-on support, rather than referring families on to other services. It is argued that, 'families appreciate the 'can do' attitude of their worker, which can be felt to be in contrast to other agencies' (DCLG, 2012: 19). The principles of responsibility and competence in the delivery of care demand that action is taken to address the needs identified, and key workers must therefore provide effective support for families rather than merely issuing ultimatums about what needs to change. They must engage with families to provide practical solutions to overcome the specific obstacles to change which they face. The act of literally "rolling up their sleeves" and "donning the marigolds"' (DCLG, 2012: 21), helping families with household cleaning and clearing jobs is also noted as an important way of building trust, since it 'signal[s] to families that the worker intends to keep their promises and is there to help' (DCLG, 2012: 21). 
Building these relationships of mutual respect through active participation enables families to see their support workers as human, as 'just normal people' (DCLG, 2012: 19). Families talk about their key worker by name, and perceive that they as an individual, rather than the service they represent, has helped improve families' lives. The relationship between key worker and family members is therefore central to family progress (DCLG, 2012), especially where families have found engagement difficult in the past, with lengthy histories of unsuccessful referrals, poor communication and depersonalised interventions. The key worker can begin building bridges and 're-opening communication with these agencies' (DCLG, 2012: 17). Through advocacy and service co-ordination, they promote the interests of the family, influencing and aligning the actions other services might take.

Understanding families and their complex biographies is described as demanding considerable empathy from the dedicated family intervention workers who are seen to be 'standing alongside the families, their difficulties and the process being put in place' (DCLG, 2012: 18). This empathy is seen as essential in understanding how things feel for the family, addressing care ethicists' attention to the responsiveness of those receiving care. Rejecting tokenistic attempts to imagine oneself in another's position, as if people are interchangeable, requires an appreciation of the unique experiences of the other (Tronto, 1993). The key worker's engagement with families is described as creating a 'feel good factor' (DCLG, 2012: 22) as families begin to see real achievements and build confidence. Key workers demonstrate recognition of selfhood by supporting individuals to fulfil ambitions and addressing connections between self-confidence and personal appearance, recognising the embodied nature of the 'self' and the connections between the emotional and embodied outcomes of care.

In terms of the final principle of recognition of loss, this involves an acknowledgement that 'wrongs cannot always be "righted"' (Smart and Neale, 1999: 196) and that families cannot always be returned to the way they were prior to a dispute or incident. This principle is less evident within the report. Whilst it positions relational work as vital to strengthening families, re-connecting estranged relatives and recognising feelings of loss, it does little to go beyond this and to address the impact of loss. I argue that interventions underpinned by a recognition of loss must also challenge the 'myth of the clean slate' (Tronto, 2013) and recognise the ways in which loss, trauma and abuse impact upon individual starting points, and opportunities for progression and change. However, the neoliberal emphasis on procedural equality, individualism and self-sufficiency prevents such individuated positioning. Therefore, whilst this section has demonstrated that the TFP model outlined in Working with Troubled Families could be seen as grounded in care ethics, the absence of an adequate recognition of loss shapes a number of challenges to care ethics within family interventions, which the next section will address.

\section{Challenges to care ethics in the Working with Troubled Families model}

Alongside these depictions of the family intervention model as characterised by care ethics, there exists an alternative neoliberal narrative, reflecting an ethic of 'justice', through its focus on universalist, legalistic approaches to imposing responsibilities upon families. Contractual arrangements for support are a significant feature of the model, based on the Dundee Families Project model which saw 'families signing up to a contract that offered a mix of support and challenge to them with a new threat of sanction if families refused help' (DCLG, 2012: 11). This language of contract is founded in the 
liberal notion of free and equal parties making fair exchange of terms for mutual benefit. Yet in the context of interventions with families who have experienced considerable loss, trauma and structural disadvantage, this approach raises questions about the degree of reciprocity involved, the relative power of the 'parties' to the 'contract' to determine conditions and the penalties for non-adherence, echoing Crawford's critique that this is 'inauthentic contractual governance' facilitating 'regulated self-regulation' (Crawford, 2003: 488). Whilst some examples are given of the benefits for family members, e.g. redecorating children's bedrooms in exchange for improved school attendance, elsewhere the benefits appear to be simply avoidance of sanctions. Central to a feminist ethics of care is the concern to avoid harm to others through an unequal distribution of power. Considering care principles therefore encourages us to critique the inauthentic use of contractual language within unequal social relationships which instead demand 'asymmetrical reciprocity' in which moral judgements are made on dialogical lines (Sevenhuijsen, 2004: 187).

The threat of sanctions is depicted as essential for the success of the family intervention model since it "concentrates the mind" of families and is a key mechanism for bringing about change' (DCLG, 2012: 28). This emphasis on rational calculations of risk and reward certainly reflects a model of individualist justice ethics, promoting personal agency and responsibility, despite the powerlessness of some families to make the necessary changes. 'Troubled families' are depicted as devious and consequently, 'Families and their problems are gripped' (DCLG, 2012: 27), 'Cases are not allowed to drift' (DCLG, 2012: 27) and doing 'too much' for families is seen as 'allowing them off the hook' (DCLG, 2012: 22). However, there is also evidence of 'care' being advocated as 'the mercy that tempers justice' (Gilligan, 1987: 36) where the key worker acts as an intermediary (DCLG, 2012: 28) in the use of sanctions imposed upon families by other agencies, calling for either acceleration or deceleration in their application. Here, there is the potential for the sanctions to be applied (or held back) with consideration of the full contexts of specific family circumstances, and thus we see a more complex interplay between justice and care ethics, which may amount to 'judging with care' (Sevenhuijsen, 1998: 4).

Key workers are described as 'persistent, tenacious and assertive' (DCLG, 2012: 23) and 'authoritative and challenging' (DCLG, 2012: 27), raising questions about how seamlessly trust and empathy can sit alongside authority and challenge. Delivering interventions within empathetic and trusting relationships is seen within this report as a strategy for making families more receptive to behaviour modification interventions since:

It is often the trust that has been built up through their honest approach with families and the practical help they have given that enables those workers to be authoritative and challenging with the families. (DCLG, 2012: 24)

Establishing a relationship of trust and respect may enable key workers to challenge families without the need to assert authority, so that: 'even though she was ordering, it didn't seem like that, it was like she showed you respect' (DCLG, 2012: 24). Therefore, whilst family experiences of authority and challenge can be impacted positively by the relational contexts of support, the converse of this is that care principles can be co-opted in the pursuit of 'justice' oriented control agendas. 
The TFP advocates the development of 'light' and 'superlight' versions of the model for smaller or less complex families (DCLG, 2012: 31), reflected in key worker caseloads of five to fifteen families for 'family intervention light' (compared to five or fewer families per key worker in the standard family intervention model advocated). This neoliberal interpretation of family intervention as 'short-term, time-limited, discrete 'interventions' delivered by disembodied experts' (Featherstone et al., 2013: 1745) inevitably reduces the time available to spend with families and build constructive relationships, thus preventing the effective incorporation of care ethics into family support and threatening the moral integrity of the programme. Furthermore, the focus on the payments-by-results criteria risks directing support workers' attentiveness from the full range of family problems to those prioritised in the financial framework. Whilst phase two of the TFP has expanded criteria for identifying families in need of support, little weight may still be given to the importance of 'softer' outcomes in improving longer-term family well-being (Batty, 2014).

There is however evidence of practitioners actively subverting the national 'troubled families' agenda with around half of local authorities having funded activities only up to the level of the attachment fee and not budgeting for outcome fees (Department for Communities and Local Government and the Department for Work and Pensions, 2013), perhaps reflecting their reluctance to engage with the payments-by-results criteria, or acknowledging that their work supports families in wider, softer, unrecognised ways (Holmes, 2015). Furthermore, local authorities are developing more empathetic local variations with a different, family friendly name, rather than the stigmatising and unhelpful label given to the national programme (Holmes, 2015), which may inhibit engagement by families experiencing multiple, complex problems (Hayden and Jenkins, 2014). There is therefore the potential for local authorities and individual practitioners to resist the central government framing of the problem (Parr and Nixon, 2009) whilst still engaging in work funded by the TFP. This has prompted the question of whether the TFP amounts to a coherent 'programme' at all (Hayden and Jenkins, 2014). Through subversion of the TFP funding streams, local authorities may be better placed to support a broader spectrum of needs experienced by disadvantaged families and to ensure that the service is characterised by a feminist ethic of care.

\section{Gendered discourses in the Troubled Families Programme}

Undertaking a Trace analysis necessitates an evaluation of the ways in which gender is played out in the policy discourse since 'care' is an historically gendered activity. The issue of gendered power relations is not explicitly identified within either of the two 'troubled families' reports in spite of the fact that gender fundamentally shapes the nature of 'family', relationships within families, and the biographies of harm experienced by family members. The gender neutral language of 'parent' and 'parenting' is used extensively within the discourse, contrasting sharply with the gendered normative judgements therein. Such discourse masks the disproportionate use of family interventions within families headed by a lone female (Parr, 2011), the reality that it is primarily mothers who 'parent' (Standing, 1999) and the highly gendered discourses within social work practices (Scourfield, 2001a, 2001b; Strega et al., 2008; Featherstone, 2014).

The Listening to Troubled Families report seeks to make sense of complex and shifting relationships through the lens of traditional, gendered and heteronormative notions of 'family' structures. The term 'casual' is used with regard to both biological parents' 
attitudes to relationships and parental responsibilities, but overlooks clear differences between the mothers' and fathers' contributions, with women left raising the child in difficult circumstances in the majority of cases. We are told that 'mothers had taken on step-children' (Casey, 2012: 48) within reconstituted families, yet new male partners are rarely attributed this identity as step-parent. In fact, the influence of male partners within the home is described as an obstruction to family life: 'the presence of partners often hindered child rearing rather than help ease the burden' (Casey, 2012: 49) - what Scourfield (2001b) describes as a discourse of fathers as 'no use'. The gendered division of parental labour therefore emerges as an important yet unacknowledged theme within Listening to Troubled Families.

Descriptions of the nature of the parenting support provided to families also reflects some considerable gendered assumptions masked by the gender neutral language of 'parenting'. Traditional domestic gender roles are reinforced within the programme, with mothers and grandmothers given more responsibility for domestic chores, child care, and for policing the behaviour of others in the household. Of course, within many of the households discussed in relation to Casey's interviews, the only 'parent' present is the mother in any case, but mothers tend to be attributed primary responsibility for children's welfare even where fathers are present and involved (Strega et al., 2008).

Mothers are viewed in the report as irresponsible simply by becoming a parent without having the necessary life skills to prepare them adequately for the role. Women who fail to meet the needs of their children due to severe depression and mental illhealth are depicted as having 'given up, being exhausted and abdicating all control for what is happening in their lives, which in turn simply reinforces their problems' (Casey, 2012: 3). In comparison to the discussion about absent fathers abdicating responsibility for parenting, there seems to be a much greater degree of responsibilisation of mothers when they 'give up' even when they (unlike the fathers) remain within the home, such that 'when they fall, they fall from a greater height' (Scourfield, 2001a: 85). The TFP thus encourages working-class women to pursue maternal and caring identities as a means of 'respectability' (Skeggs, 1997), whilst reinforcing notions of working-class men as 'risky' with respect to caring responsibilities (Scourfield, 2001b).

Women are also implicitly responsiblised within Casey's report for male violence in the context of domestic relationships, drawing upon long-standing social work assumptions about women's responsibility for protecting children from abuse (Scourfield, 2001a). In three quarters of those families interviewed by Casey, the mother had suffered domestic abuse, and in some cases their daughters also suffered violence in their relationships (Casey, 2012: 55), but the evident gender dimensions of such abuse are at times lost within a gender neutral discussion of the 'endemic abuse' existing between parents, siblings and parent and child (Casey, 2012: 2).

Scourfield (2001b) has argued that even where feminism has influenced social work practice by drawing attention to men's relative power and the unequal distribution of domestic labour, this has not acted to reduce levels of surveillance on women within the home. In order to pursue a feminist ethics of care within family intervention services, these gendered inequalities in policy and practice must be addressed and services must engage with the specific dynamic of relationships within each unique family, including considering men as a potential resource, not just as a risk (Featherstone, 2014). 


\section{Conclusion}

This paper has traced the discourse constructed in two key TFP policy documents through the lens of care ethics, highlighting tensions between 'care' and 'justice' orientations in the neoliberal family intervention model. However, the fact that the TFP is not a monolithic regime, but encompasses varied local practices, offers considerable opportunity for services to shape structures of support for vulnerable families. Evaluations of TFP projects must reflect upon specific local contexts and professional identities of the staff delivering the programmes. The ethics of care offer a valuable moral framework by which to evaluate the potential of such programmes as viable alternatives to neoliberal measures of success.

The potential of care ethics in supporting vulnerable families lies in the value assigned to each individual human being and his or her capacity to engage in meaningful relationships. The family intervention model advocated within the TFP can be seen as having the potential to offer such support in the way that key workers relate to others as human beings, demonstrate attentiveness to their diverse needs, and take responsibility for addressing those needs in specific family contexts. However, managerialist tendencies provide challenges to the integration of care ethics within services to support families with complex needs. The development of a financial framework which incentivises work to address a fairly narrow range of problems, and the time limits imposed within 'light' and 'superlight' versions of support diminish the relational capacities of services to identify and respond to families' needs.

Moreover, engaging with a distinctly feminist ethic of care would require gender inequalities to be rendered more visible and for family support services to consider underlying assumptions around the gendered distribution of 'caring' responsibilities and the subsequent impact upon women's social and economic independence. Projects promoting the 'empowerment' of the family often serve only to strengthen existing power relations within the family, and between family (especially mothers) and local authority services (Bond-Taylor, 2014), promoting a feminine ethic of care which reinforces women's domestic and family responsibilities. Interventions within families which fail to address such concerns or to prioritise gender equality run the risk of reproducing patriarchal relations and subjecting women to additional social control.

\section{References}

Bailey, N. (2012) 'Policy based on unethical research', Poverty and Social Exclusion UK, 25 October 2012, http://www.poverty.ac.uk/news-and-views/articles/policy-built-unethical-research [accessed $11 / 12 / 2015]$.

Barnes, M. (2012) Care in Everyday Life: An Ethic of Care in Practice, Bristol: The Policy Press.

Batty, E. (2014) 'Learning and soft outcomes: evidence from intensive intervention projects', Social Policy and Society, 13, 3, 357-69.

Bond-Taylor, S. (2014) 'Dimensions of family empowerment in work with so called "troubled" families', Social Policy and Society, 14, 3, 371-84.

Casey, L. (2012) Listening to Troubled Families: A Report by Louise Casey CB, London: Department for Communities and Local Government.

Casey, L. (2013) Head of Troubled Families, Louise Casey Speaks at the Association of Directors of Children's Services (ADCS) Annual Conference, 4/7/2013, London: Department for Communities and Local Government. 
Crawford, A. (2003) "Contractual governance" of deviant dehaviour', Journal of Law and Society, 30, 4, 479-505.

Crossley, S. (2016) "'Realising the (troubled) family", "crafting the neoliberal state"', Families, Relationships and Societies 5, 2, 263-79.

Department for Communities and Local Government (DCLG) (2012) Working with Troubled Families: A Guide to the Evidence and Good Practice, December 2012, London: Department for Communities and Local Government.

Department for Communities and Local Government and the Department for Work and Pensions (2013) Programmes to Help Families Facing Multiple Challenges, 3 December 2013, London: National Audit Office.

Engster, D. (2007) The Heart of Justice: Care Ethics and Political Theory, Oxford: Oxford University Press.

Featherstone, B. (2014) 'Working with fathers: risk or resource?', in J. Ribbens McCarthy, C. A. Hooper and V. Gillies (eds.), Family Troubles? Exploring Changes and Challenges in the Lives of Children and Young People, Bristol: Policy Press.

Featherstone, B., Morris, K. and White, S. (2013) 'A marriage made in hell: early intervention meets child protection', British Journal of Social Work, 44, 7, 1735-49.

Gilligan, C. (1982) In a Different Voice: Psychological Theory and Women's Development, Cambridge, MA: Harvard University Press.

Gilligan, C. (1987) 'Moral orientation and moral development', reprinted in V. Held (ed.) (1995) Justice and Care: Essential Readings in Feminist Ethics, Oxford: Westview Press.

Gregg, D. (2010) Family Intervention Projects: a Classic Case of Policy-Based Evidence, Centre for Crime and Justice Studies, http://www.crimeandjustice.org.uk/opus1786/Family_intervention_projects.pdf [accessed 14/03/2013].

Hayden, C. and Jenkins, C. (2014) "Troubled Families" Programme in England: "wicked problems" and policy-based evidence', Policy Studies, 35, 6, 631-49.

Held, V. (2002) 'Care and the extension of markets', Hypatia, 17, 2, 19-33.

Holmes, D. (2015) 'Delivering phase 1 of the Troubled Families Programme', in K. Davies (ed.), Social Work with Troubled Families: A Critical Introduction, London: Jessica Kingsley.

Hughes, C. (2002) Key Concepts in Feminist Theory and Research, London: Sage.

Levitas, R. (2012) There May be 'Trouble' Ahead: What We Know about Those 120,000 'Troubled' Families, Poverty and Social Exclusion in the UK, Working Paper No. 3, 21 February 2012.

Parr, S. (2011) 'Family policy and the governance of anti-social behaviour in the UK: women's experiences of intensive family support', Journal of Social Policy, 40, 4, 717-37.

Parr, S. and Nixon, J. (2009) 'Family intervention projects: sites of subversion and resilience', in M. Barnes and D. Prior (eds.), Subversive Citizens: Power, Agency and Resistance in Public Services, Bristol: Policy Press.

Robinson, F. (2010) 'After liberalism in world politics? Towards an international political theory of care', Ethics and Social Welfare, 4, 2, 130-44.

Scourfield, J. B. (2001a) 'Constructing women in child protection work', Child and Family Social Work, 6, $1,77-87$.

Scourfield, J. B. (2001b) 'Constructing men in child protection work', Men and Masculinities, 4, 1, $70-89$.

Sevenhuijsen, S. (1998) Citizenship and the Ethics of Care: Feminist Considerations on Justice, Morality and Politics, London: Routledge.

Sevenhuijsen, S. (2003) 'The place of care: the relevance of the feminist ethic of care for social policy', Feminist Theory, 4, 2, 179-97.

Sevenhuijsen, S. (2004) 'Trace: a method for normative policy analysis from the ethic of care', in S. Sevenhuijsen and A. Svab (eds.), The Heart of the Matter: The Contribution of the Ethic of Care to Social Policy in Some New EU Member States, Peace Institute, Institute for Contemporary Social and Political Studies.

Skeggs, B. (1997) Formations of Class and Gender, London: Sage.

Smart, C. and Neale, B. (1999) Family Fragments? Cambridge: Polity Press. 
Squires, J. (1999) Gender in Political Theory, Cambridge: Polity Press.

Strega, S., Fleet, C., Brown, L., Dominelli, L., Callahan, M. and Walmsley, C. (2008) 'Connecting father absence and mother blame in child welfare policies and practice', Children and Youth Services Review, 30, 7, 705-16.

Tronto, J. (1993) Moral Boundaries: A Political Argument for an Ethic of Care, London: Routledge.

Tronto, J. (2013) Caring Democracy: Markets, Equality, and Justice, New York and London: New York University Press.

Ward, L. (2015) 'Caring for ourselves? Self-care and neoliberalism', in M. Barnes, W. Brannelly, L. Ward and N. Ward (eds.), Ethics of Care: Critical Advances in International Perspective, Bristol: Policy Press. 